\title{
BIOPSYCHOSOCIAL
}

MEDICINE

\section{Profile of mood states and stress-related biochemical indices in long-term yoga practitioners}

Yoshihara et al. 


\title{
Profile of mood states and stress-related biochemical indices in long-term yoga practitioners
}

\author{
Kazufumi Yoshihara ${ }^{1,2^{*}}$, Tetsuya Hiramoto ${ }^{1}$, Nobuyuki Sudo ${ }^{1}$ and Chiharu Kubo ${ }^{1}$
}

\begin{abstract}
Background: Previous studies have shown the short-term or intermediate-term practice of yoga to be useful for ameliorating several mental disorders and psychosomatic disorders. However, little is known about the long-term influences of yoga on the mental state or stress-related biochemical indices. If yoga training has a stress-reduction effect and also improves an individual's mental states for a long time, long-term yoga practitioners may have a better mental state and lower stress-related biochemical indices in comparison to non-experienced participants. This study simultaneously examined the differences in mental states and urinary stress-related biochemical indices between long-term yoga practitioners and non-experienced participants.

Methods: The participants were 38 healthy females with more than 2 years of experience with yoga (long-term yoga group) and 37 age-matched healthy females who had not participated in yoga (control group). Their mental states were assessed using the Profile of Mood States (POMS) questionnaire. The level of cortisol, 8hydroxydeoxyguanosine $(8-\mathrm{OHdG})$ and biopyrrin in urine were used as stress-related biochemical indices.

Results: The average self-rated mental disturbance, tension-anxiety, anger-hostility, and fatigue scores of the longterm yoga group were lower than those of the control group. There was a trend toward a higher vigor score in the long-term yoga group than that in the control group. There were no significant differences in the scores for depression and confusion in the POMS between the two groups. The urine 8-OHdG concentration showed a trend toward to being lower in the long-term yoga group in comparison to the control group. There were no significant differences in the levels of urine biopyrrin or cortisol.
\end{abstract}

Conclusions: The present findings suggest that long-term yoga training can reduce the scores related to mental health indicators such as self-rated anxiety, anger, and fatigue.

\section{Background}

Yoga is an ancient technique of promoting health through exercises, regulation of breathing, and meditation. The practice of yoga has increased in many countries, such as the United States (US), the UK, and Japan. The popularity of yoga in US adults is evident by the estimated increase in participation from $3.7 \%$ in 1997 , $5.1 \%$ in 2002 , to $6.1 \%$ in 2007 [1,2]. Yoga has been reported to have various therapeutic effects. Studies have shown that the practice of yoga reduces perceived stress and negative feelings and improves mental and

\footnotetext{
*Correspondence: kyoshiha@cephal.med.kyushu-u.ac.jp 'Department of Psychosomatic Medicine, Graduate School of Medical Sciences, Kyushu University, 3-1-1 Maidashi, Higashiku, Fukuoka, Japan Full list of author information is available at the end of the article
}

physical symptoms [3-6]. Yoga has therapeutic benefits not only for various mental disorders [7-10] but also for some physical diseases, such as asthma [11], hypertension [12], rheumatoid arthritis [13], migraines [14], musculoskeletal disorders [15], cancer-related symptoms [16] and other disorders [17], most of which are related to mental factors or mental states, or are aggravated by stress.

It has been demonstrated that the practice of yoga improves the mental state by lowering the levels of anxiety, depression and anger [18-21]. Lavey et al. indicated that tension-anxiety, depression, anger-hostility, fatigue, and confusion in psychiatric inpatients were improved following at least one yoga session [19]. Manocha et al. indicated that a 4 month intervention with yoga reduced

\section{Biomed Central}


anger-hostility and fatigue scores in asthma patients [20]. Sareen et al. demonstrated that 12 weeks' intervention with yoga reduced tension-anxiety, depression, anger-hostility, fatigue, and confusion scores in chronic pancreatitis patients [21]. While these limited studies have revealed that yoga can improve the self-rated tension-anxiety, depression, anger-hostility, or fatigue scores, this improvement has only been shown after short-term or intermediate-term practice of yoga. The potential effects of long-term yoga practice on a person's mental state have not been investigated.

It is known that the mental state can influence the hypothalamic-pituitary-adrenal (HPA) axis and alter the cortisol levels. Cortisol, secreted from the adrenal cortex, is a biochemical index of HPA axis activation, and is an important marker related to psychological stress. Some studies have demonstrated that the long-term practice of meditation, which is one of the components of yoga, does not to lead to any significant difference in the baseline cortisol level between practitioners and control participants [22-24]. With regard to yoga, however, Vera et al. showed that there was a significantly higher level of baseline cortisol in long-term yoga practitioners than in the control participants [25].

Besides cortisol, there have been several studies comparing other biochemical indices of experienced meditation practitioners with those of less experienced practitioners, or non-experienced participants [24,26-29]. For example, catecholamine levels, such as norepinephrine, epinephrine and vanillylmandelic acid (VMA), are representative examples of stress-related biochemical indices. Lang et al. reported the daily urinary excretion of norepinephrine, epinephrine, and VMA to all be higher in qualified meditators compared with less experienced practitioners [26]. On the other hand, Infante et al. reported that the urinary levels of norepinephrine and epinephrine in the meditation group were lower than those in the control group [24,27], and Walton et al. found low concentrations of urinary VMA in meditation practitioners in comparison with nonpracticing participants [28]. Therefore, the impact of longterm medication on the catecholamine levels appears to be controversial, and further studies are needed to conclusively determine the impact of long-term meditation on stress levels.

Recently, urinary stress-related biochemical indices, such as 8-hydroxydeoxyguanosine (8-OHdG) and biopyrrin, have been used to assess the psychological stress because the blood sampling itself is invasive and can be associated with psychological stress [30-33]. The urinary 8-OHdG level is a putative biomarker of total systemic oxidative stress [34] and psychological distresses are associated with oxidative damage [30]. Biopyrrin, which is an oxidative metabolite of bilirubin, is also one of the urinary stress-related biochemical indices [31-33]. However, there have been no previous studies comparing the 8-OHdG or biopyrrin levels of experienced yoga practitioners with those of less experienced practitioners, or non-experienced participants.

If yoga training has a stress-reduction effect and also improves an individual's mental states for a long time, long-term yoga practitioners may have a better mental state, which would be indicated by lower scores for mental disturbance, anxiety, anger, depression, and fatigue, and lower stress-related biochemical indices in comparison to non-experienced participants. Therefore, the current study simultaneously examined the differences in mental states and urinary stress-related biochemical indices between long-term yoga practitioners and non-experienced participants. The purpose of this study was to examine the beneficial effects of long-term yoga on indicators of psychological distress, such as anxiety, anger, depression, and fatigue levels in the profile of mood states questionnaire (POMS), and on the stress-related biochemical indices, such as biopyrrin and 8-OHdG levels, in healthy individuals.

\section{Methods}

\section{Participants and data collection}

This study evaluated thirty-eight healthy, adult females with more than 2 years of experience with yoga (longterm yoga group: we defined more than 2 years of experience as being long-term in this study) and 37 agematched healthy, adult females who had no experience with yoga (control group). The participants in the longterm yoga group were recruited from qualified yoga instructors and their students who had more than 2 years of yoga experience from ten yoga training centers in Fukuoka, Kumamoto, and Kagoshima prefectures of Japan. The control group participants were recruited from among the acquaintances of the qualified yoga instructors in the same prefectures. The following exclusion criteria were applied to participants: (i) age $<20$ years old or $>60$ years old; (ii) taking medication including supplements in the last 1 month prior to the experiment; (iii) having an illness; or (iv) having a past history of a physical or mental illness. All participants received 500 yen (about $\$ 5.50$ ) for participating in this study. All participants received detailed information on the purpose about the study and provided written informed consent. The participants who agreed were then handed two questionnaires, a paper cup, a tube with a screw cap, and a self-addressed parcel. Each participant collected her urine at home and she answered the questionnaires at the same time. The urine and the questionnaires was sent via a parcel delivery service, which used a freezer van to keep the samples frozen at $-18^{\circ} \mathrm{C}\left(-0.4^{\circ} \mathrm{F}\right)$, as soon as possible. This study was 
approved by the Institutional Review Board at Kyushu University.

\section{Yoga in the long-term yoga group}

The long-term yoga group participants had practiced yoga in sessions of an average of $2.94 \pm 2.04$ days a week (Range: 1-7), with a duration of $1.37 \pm 0.49$ hours each day (Range: $0.5-3.0$ ), for $3.70 \pm 2.27$ years (Range: $2-14$ ) on average. The calculated mean total hours of yoga exercise using these values was $1174 \pm 2243$ (Range: 10413104). They practiced the structured classic postures (Shavasana, Tadasana, Ardha Kati Chakrasana, Pada Hastasana, Ardha Chakrasana, Shashankasana, Ardha Ushtrasana, etc.), breathing exercises (Kapalabhati Pranayama, Anuloma Pranayama, Bhramari Pranayama, etc.), and meditation (Om meditation etc.). In addition, most of them mainly practiced the structured classic postures.

\section{Urine sampling}

Urine samples were taken from all participants for the quantification of biopyrrin, 8-OHdG, cortisol and creatinine. The participants were asked to avoid vigorous exercise and heavy psychological stress for 24 hours prior to urine collection. Urine was collected at 6:009:00 am, and $2 \mathrm{ml}$ of urine from each participant was stored at $-80^{\circ} \mathrm{C}$ until it was analyzed. The urinary biopyrrin, cortisol, and 8-OHdG concentrations were measured by enzyme-linked immunosorbent assay kits (Shino-Test, Tokyo, Japan, Oxford Biomedical Research, Inc. MI, and Nikken Seil Co., Ltd, Shizuoka, Japan, respectively). The urine creatinine concentration was analyzed using the Accuras Auto-Cre diagnosis kit (Shino-Test, Tokyo, Japan) and biopyrrin, 8-OHdG and cortisol concentrations were corrected based on the urine creatinine concentration.

\section{Questionnaire}

A self-completed questionnaire about demographic and yoga-related characteristics, and the POMS (Educational and Industrial Testing Service, San Diego, CA) questionnaire were given to all of the participants. The self-completed questionnaire included questions about age, race, education, mean number of hours per day and mean number of days per week, spent practicing yoga at home or in a yoga center, and years of yoga experience. The POMS questionnaire assesses six mood subscales: tension-anxiety, depression, anger-hostility, vigor, fatigue, and confusion. High vigor scores reflect a good mood or emotion, and low scores in the other subscales reflect a good mood or emotion. The total mood disturbance score was computed by adding the five negative subscale scores (tension-anxiety, depression, anger-hostility, vigor, fatigue, and confusion) and subtracting the vigor score.
Higher scores for the total mood disturbance score indicate a greater degree of mood disturbance. These scores have been widely used in the assessment of mood states. Yokoyama et al. previously translated the 65-item scale in the POMS into Japanese, and demonstrated the reliability and validity of the Japanese version of the POMS in Japanese participants [35]. The Japanese version of the POMS (Kaneko Shobo Co., Tokyo, Japan) was used for the present study.

\section{Statistical analysis and sample size}

Statistical analyses were performed by using a statistical software package (PASW Statistics 18, version 18.0.0 for Windows; SPSS Inc., Chicago, IL, USA). The unpaired $t$ test and the Pearson's chi-square test were used to compare the age and education between the long-term yoga group and the control group, respectively. The MannWhitney U-test was used to compare the biopyrrin, 8OHdG and cortisol concentrations, which were corrected based on the urine creatinine concentration, and the scores of questionnaires between the long-term yoga group and the control group. The Spearman rank correlation was used to test the relationship between the total hours of yoga exercise and the POMS scores. Differences of $p<0.05$ were considered to be statistically significant.

We estimated that a sample size of 35 in each group would allow us to detect any difference between the groups in some POMS scores with $80 \%$ power $(\alpha=$ 0.05 ) based on the mean and standard deviation of each POMS score reported in a previous study [21]. This sample size would also be sufficient to detect a meaningful difference in cortisol between the groups with reference to the sample size of the previous study [25].

\section{Results}

\section{Participant demographics}

The demographic data of the participants including their age, race, and education are shown in Table 1. None of these variables were significantly different between the control and the long-term yoga groups.

\section{Profile of mood states}

There were some significant differences between the control and the long-term yoga group in the POMS scores (Table 2). The long-term yoga group showed a lower total mood disturbance $(p=0.015)$, tension-anxiety $(p=0.017)$, anger-hostility $(p=0.007)$, and fatigue score $(p=0.008)$ in the POMS. There was a trend toward a higher vigor score in the long-term yoga group than in the control group $(p=0.082)$. There were no significant differences in the scores for depression and confusion in the POMS. 
Table 1 Demographic of the control and long-term yoga groups

\begin{tabular}{|c|c|c|c|c|}
\hline Characteristics & Control group $(n=37)$ & Long-term yoga group $(n=38)$ & Statistic & $p$-value \\
\hline Age [Mean (standard deviation)] & $34.43(8.16)$ & $33.84(7.33)$ & $t=0.330$ & 0.743 \\
\hline Range & $(22-49)$ & $(22-49)$ & & \\
\hline \multicolumn{5}{|l|}{ Race (\%) } \\
\hline Asian & $100(n=37)$ & $100(n=38)$ & & \\
\hline Education (\%) & & & $\chi^{2}=0.958$ & 0.812 \\
\hline Junior H.S. graduate & $0.0(n=0)$ & $2.6(n=1)$ & & \\
\hline H.S. graduate & $24.3(n=9)$ & $23.7(n=9)$ & & \\
\hline Junior college graduate & $37.8(n=14)$ & $42.1(n=16)$ & & \\
\hline College graduate & $29.7(n=11)$ & $31.6(n=12)$ & & \\
\hline Blank & $8.1(n=3)$ & $0.0(n=0)$ & & \\
\hline
\end{tabular}

The unpaired $t$-test and Pearson's chi-square test were used to compare the age and education levels between the long-term yoga group and control group, respectively.

\section{Stress-related biochemical indices}

The urine 8-OHdG concentration showed a trend toward being lower in the long-term yoga group in comparison to the control group ( $p=0.067$, Table 3 ). There were no significant differences in the levels of urine biopyrrin or cortisol (Table 3).

\section{Correlation between the total hours of yoga exercise and the POMS scores in the long-term yoga group}

To investigate the "dose" effect on the POMS scores by the total hours spent in yoga exercise, we calculated the correlation between the total hours of yoga exercise and the mental disturbance, tension-anxiety, anger-hostility, and fatigue scores on the POMS in the long-term yoga group. However, no correlations were identified between them (data not shown).

\section{Discussion}

The present study demonstrated that long-term yoga practitioners have lower mental disturbance, tensionanxiety, anger-hostility, and fatigue scores in the POMS test in comparison to non-experienced participants, although there were no significant differences in the

Table 2 Scores of Profile of Mood States (POMS) in the control and long-term yoga groups

\begin{tabular}{ccc}
\hline Variable & $\begin{array}{c}\text { Control } \\
\text { group }\end{array}$ & $\begin{array}{c}\text { Long-term yoga } \\
\text { group }\end{array}$ \\
\hline $\begin{array}{c}\text { Profile of Mood States (POMS) } \\
\text { Total mood disturbance } \\
\text { score }\end{array}$ & $34.11 \pm 31.46$ & $18.03 \pm 31.54 *$ \\
Tension-Anxiety & $9.86 \pm 6.01$ & $6.95 \pm 5.84^{*}$ \\
Depression & $9.81 \pm 8.52$ & $7.89 \pm 9.46$ \\
Anger-Hostility & $10.08 \pm 7.40$ & $6.29 \pm 6.97 * *$ \\
Vigor & $12.16 \pm 5.59$ & $15.00 \pm 6.57$ \\
Fatigue & $8.65 \pm 5.94$ & $5.47 \pm 5.31 * *$ \\
Confusion & $7.86 \pm 4.73$ & $6.42 \pm 4.68$ \\
\hline
\end{tabular}

Results are presented as the means \pm standard deviation (SD). * $p<0.05$; **: $p<0.01$ levels of urinary stress-related markers. This is the first study to demonstrate that long-term yoga practitioners have a better mental state than healthy participants who do not engage in yoga. These findings suggest that ongoing yoga training reduces the level of mental disturbance, anxiety, anger, and fatigue not only over the short- or intermediate-term, but also over a long term.

Yoga was found to be as effective as relaxation in reducing anxiety [5]. A systematic review of the use of yoga to treat anxiety suggested that yoga may be beneficial for different anxiety disorders [4]. Waelde et al. indicated that an intervention consisting of a six-session yoga program reduced the anxiety of dementia caregivers who did not have an anxiety disorder [36]. In addition, a week of yoga practice prevented an increase in anxiety among flood survivors [37]. Moreover, significant reductions were shown for anger and anxiety symptoms in participants who had been diagnosed with unipolar major depression in partial remission and who completed 20 yoga sessions [9]. These reports and the present results suggest that the anxiolytic and relaxational effects of yoga may continue for an extended period.

Regarding the level of depression in the current study, there was no significant difference between the depression score in the long-term yoga group and that in the control group, which was unexpected. Previous studies of yoga for depression suggest that yoga may have

Table 3 Urine concentrations of cortisol, 8-hydroxydeoxyguanosine (8-OHdG), and biopyrrin in the control and long-term yoga groups

\begin{tabular}{lcc}
\hline Variable & Control group & Long-term yoga group \\
\hline Urine concentration & & \\
Cortisol $(\mu \mathrm{g} / \mathrm{gCre})$. & $0.951 \pm 0.457$ & $0.803 \pm 0.358$ \\
8-OHdG $(\mu \mathrm{g} / \mathrm{gCre})$. & $0.125 \pm 0.061$ & $0.109 \pm 0.080$ \\
Biopyrrin $(\mathrm{u} / \mathrm{gCre})$. & $1.216 \pm 0.410$ & $1.266 \pm 0.736$ \\
\hline
\end{tabular}

Results are presented as the means \pm standard deviation (SD). 
beneficial effects not only among depressive patients [9], but also non-patients with elevated symptoms of depression $[38,39]$. However, the current results indicated that the mean depressive scores of both the long-term yoga group and the control group were lower than 11, which is equivalent to 50 based on $\mathrm{T}$-score conversion (the $\mathrm{T}$ score table is attached to the Japanese version of the POMS). Therefore, it may be difficult for non-depressive healthy participants to reduce their depressive score in the POMS. Like the mean depressive scores, the mean confusion scores in both groups were lower than 8.5, which is equivalent to 50 based on the T-score conversion. Therefore, there was limited potential for there to be any change in the confusion score in the POMS.

On the other hand, we could not find a "dose" effect for yoga with regard to the mental disturbance, tensionanxiety, anger-hostility, and fatigue scores on the POMS in the long-term yoga group. The mean scores in the long-term yoga group were lower than those in the control group, but the scores in the control group were lower than the equivalent values of 50 based on the Tscore conversion, suggesting the presence of a floor effect. In other words, it is speculated that the scores of mental disturbance, tension-anxiety, anger-hostility, and fatigue on the POMS may not decrease after a certain point within 2 years, even if practitioners continue to exercise yoga. A longitudinal study is needed to verify this speculation.

As for urinary 8-OHdG, previous studies have shown that a depressive state affects female 8-OHdG levels in leukocytes [40,41]. Forlenza and Miller also reported that severely depressed individuals had increased serum levels of 8-OHdG in comparison to healthy individuals [42]. In the present study, the urinary 8-OHdG level in the long-term yoga group tended to be lower than that in the control group, although there was no significant difference between the depression score of the POMS in the long-term yoga group and that in the control group. Psychological distress, not depression, may be important to increasing the concentration of urinary 8-OHdG. Further studies are needed to clarify the relationship between 8-OHdG and psychological distress.

Concerning urinary biopyrrin, several studies have indicated that the urinary excretion of biopyrrins is higher in patients with psychiatric disorders, such as schizophrenia [31,32] and it increases due to psychological stress [33]. However, the current results showed no significant difference between the urinary biopyrrin levels of the long-term yoga group and that of the control group. This may be because it is difficult for healthy people to reduce their concentration of urinary biopyrrin by yoga training because it would appear that their urinary excretion of biopyrrins, in healthy people, is already stable at a lower concentration.
Cortisol is an accepted objective stress-related biological marker, because dysregulation of the level of cortisol is related to pathologies associated with stress-related symptoms, such as anxiety, depression, and negative affect [43-45]. The decrease in cortisol soon after yoga practice shown by West et al. [46] was similar to that seen in many types of interventions to reduce stress, such as meditation $[22,47,48]$ and progressive muscle relaxation [49]. On the other hand, Vera et al. showed that a long-term yoga group displayed higher baseline cortisol levels than control participants [25]. This result was inconsistent with the present result which showed that the baseline cortisol level of the long-term yoga group was not significantly different from that of the control group. As both Vera et al.'s study and our study are cross-sectional studies, further research is needed to conclusively determine how baseline cortisol levels change over time in long-term yoga practitioners.

There are several limitations in this study. First, a relatively small number of participants were examined in this study. However, we were still able to demonstrate significant differences in some POMS scores because we properly estimated the sample size. Second, the POMS scores, some of which seemed to be influenced by the menstrual cycle, and stress-related biochemical indices were assessed only once throughout the study. Third, it was impossible to discriminate whether the practice of yoga improved the participant's mental state, or whether practitioners who had a good mental state continued to practice yoga, because this study was a cross-sectional study. Although the results must be interpreted with caution, it is possible to conclude that the improvement of mental health with yoga may continue for an extended period, because there is ample evidence that short-term or intermediate-term practice of yoga improves the participants' mental status. The fourth limitation is that the participants were only females. The long-term practice of yoga may have little effect on males. However, mood improvements by yoga are probably not related to gender in healthy participants, because Lavey et al. demonstrated that mood improvement with yoga practice was not related to gender in psychiatric inpatients [19]. Fifth, the comparison of baseline demographics is limited. We did not measure the current psychological stress levels except by using the POMS, or current exposure to situations likely to cause increased or decreased stress, such as lifestyle, work situation, any other forms of physical exercise or relaxation techniques. Also, we did not confirm whether the total hours of yoga exercise in the long-term yoga group were true, because this information was selfreported, and whether participants had actually avoided vigorous exercise and heavy psychological stress for 24 hours prior to testing. The sixth limitation is that we 
defined more than 2 years of experience as long-term in this study. Further research is needed to elucidate the far longer-term effects of yoga practice. Finally, the current study measured urinary biopyrrin and baseline cortisol concentrations as stress-related biochemical indices, which are unsuitable or insufficient to assess the mental state of healthy individuals. A multifaceted approach combining the assessment of more suitable stress-related biological markers such as the immune, endocrine, or autonomic nervous systems, and brain function, are important to more accurately assess the mental state of healthy individuals.

Despite these limitations, the present findings suggest that long-term yoga training can reduce the score related to mental health indicators such as self-rated anxiety, anger, and fatigue. Long-term yoga training may affect mental well-being and be useful to prevent mental disorders over an extended period. Further studies that measure self-rated mental states, stress-related biomarkers of the immune, endocrine, autonomic nervous systems, and brain function simultaneously are needed to verify the beneficial effects of yoga and to elucidate the mechanism(s) responsible for the benefits that are associated with yoga.

\section{Conclusion}

The present findings suggest that long-term yoga training can reduce the scores related to mental health indicators such as self-rated anxiety, anger, and fatigue.

\section{Abbreviations \\ POMS: Profile of Mood States; 8-OHdG: 8-hydroxydeoxyguanosine; HPA: hypothalamic-pituitary-adrenal; VMA: vanillylmandelic acid; SD: standard deviation.}

\section{Acknowledgements}

This study was supported by grants from the Meiji Yasuda Life Foundation of Health and Welfare, and the Japan Yoga Therapy Society Research Grant. We would like to thank Mr. Izuru Shioji of Shino-Test Co., Inc. for measuring the urine biopyrrin and creatinine concentration.

\section{Author details}

'Department of Psychosomatic Medicine, Graduate School of Medical Sciences, Kyushu University, 3-1-1 Maidashi, Higashiku, Fukuoka, Japan. ${ }^{2}$ Division of Cerebral Integration, Department of Cerebral Research, National Institute for Physiological Sciences, 38 Myodaiji-Nishigonaka, Okazaki, Aichi, Japan.

\section{Authors' contributions}

KY conceived the study, participated in the design of the study, carried out data collection, performed the statistical analysis and drafted the manuscript. $\mathrm{TH}$ participated in the design of the study and carried out data collection. NS evaluated the results of the study and reviewed the manuscript. CK participated in the design and coordination of the study and reviewed the manuscript. All authors read and approved the final manuscript.

\section{Competing interests}

The authors declare that they have no competing interests.

Received: 23 February 2011 Accepted: 3 June 2011

Published: 3 June 2011

\section{References}

1. Birdee GS, Legedza AT, Saper RB, Bertisch SM, Eisenberg DM, Phillips RS: Characteristics of yoga users: results of a national survey. J Gen Intern Med 2008, 23:1653-1658.

2. Barnes PM, Bloom B, Nahin RL: Complementary and alternative medicine use among adults and children: United States, 2007. Natl Health Stat Report 2008, 12: 1-23.

3. Granath J, Ingvarsson S, von TU, Lundberg U: Stress management: a randomized study of cognitive behavioural therapy and yoga. Cogn Behav Ther 2006, 35:3-10.

4. Kirkwood G, Rampes H, Tuffrey V, Richardson J, Pilkington K: Yoga for anxiety: a systematic review of the research evidence. Br J Sports Med 2005, 392:884-891.

5. Smith C, Hancock H, Blake-Mortimer J, Eckert K: A randomised comparative trial of yoga and relaxation to reduce stress and anxiety. Complement Ther Med 2007, 15:1277-83.

6. Luebbert K, Dahme B, Hasenbring M: The effectiveness of relaxation training in reducing treatment-related symptoms and improving emotional adjustment in acute non-surgical cancer treatment: a metaanalytical review. Psychooncology 2001, 10:490-502.

7. Descilo T, Vedamurtachar A, Gerbarg PL, Nagaraja D, Gangadhar BN, Damodaran B, Adelson B, Braslow LH, Marcus S, Brown RP: Effects of a yoga breath intervention alone and in combination with an exposure therapy for post-traumatic stress disorder and depression in survivors of the 2004 South-East Asia tsunami. Acta Psychiatr Scand 2010, 121:289-300.

8. Carei TR, Fyfe-Johnson AL, Breuner CC, Brown MA: Randomized controlled clinical trial of yoga in the treatment of eating disorders. $J$ Adolesc Health 2010, 46:346-351.

9. Shapiro D, Cook IA, Davydov DM, Ottaviani C, Leuchter AF, Abrams M: Yoga as a Complementary Treatment of Depression: Effects of Traits and Moods on Treatment Outcome. Evid Based Complement Alternat Med 2007 4:493-502

10. Duraiswamy G, Thirthalli J, Nagendra HR, Gangadhar BN: Yoga therapy as an add-on treatment in the management of patients with schizophrenia-a randomized controlled trial. Acta Psychiatr Scand 2007, 116:226-232.

11. Nagarathna R, Nagendra HR: Yoga for bronchial asthma: a controlled study. Br Med J 1985, 291:1077-1079.

12. Vijayalakshmi P, Bhavanani AB, Patil A, Babu K: Modulation of stress induced by isometric handgrip test in hypertensive patients following yogic relaxation training. Indian J Physiol Pharmacol 2004, 48:59-64.

13. Evans S, Moieni M, Taub R, Subramanian SK, Tsao JC, Sternlieb B, Zeltzer LK: lyengar yoga for young adults with rheumatoid arthritis: results from a mixed-methods pilot study. J Pain Symptom Manage 2010, 39:904-913.

14. John PJ, Sharma N, Sharma CM, Kankane A: Effectiveness of yoga therapy in the treatment of migraine without aura: a randomized controlled trial. Headache 2007, 47:654-661.

15. Sherman KJ, Cherkin DC, Erro J, Miglioretti DL, Deyo RA: Comparing yoga, exercise, and a self-care book for chronic low back pain: a randomized, controlled trial. Ann Intern Med 2005, 143:849-856.

16. Moadel AB, Shah C, Wylie-Rosett J, Harris MS, Patel SR, Hall CB, Sparano JA: Randomized controlled trial of yoga among a multiethnic sample of breast cancer patients: effects on quality of life. J Clin Oncol 2007, 25:4387-4395.

17. Cade WT, Reeds DN, Mondy KE, Overton ET, Grassino J, Tucker S, Bopp C, Laciny E, Hubert S, Lassa-Claxton S, Yarasheski KE: Yoga lifestyle intervention reduces blood pressure in HIV-infected adults with cardiovascular disease risk factors. HIV Med 2010, 11(6):379-388.

18. Michalsen A, Grossman P, Acil A, Langhorst J, Lüdtke R, Esch T, Stefano GB, Dobos GJ: Rapid stress reduction and anxiolysis among distressed women as a consequence of a three-month intensive yoga program. Med Sci Monit 2005, 11:CR555-561.

19. Lavey R, Sherman T, Mueser KT, Osborne DD, Currier M, Wolfe R: The effects of yoga on mood in psychiatric inpatients. Psychiatr Rehabil J 2005, 28:399-402.

20. Manocha R, Marks GB, Kenchington P, Peters D, Salome CM: Sahaja yoga in the management of moderate to severe asthma: a randomised controlled trial. Thorax 2002, 57:110-5.

21. Sareen S, Kumari V, Gajebasia KS, Gajebasia NK: Yoga: a tool for improving the quality of life in chronic pancreatitis. World J Gastroenterol 2007, 13:391-397. 
22. Jevning R, Wilson AF, Smith WR: The transcendental meditation technique, adrenocortical activity, and implications for stress. Experientia 1978, 34:618-619.

23. Michaels RR, Parra J, McCann DS, Vander AJ: Renin, cortisol, and aldosterone during transcendental meditation. Psychosom Med 1979, 41:50-54.

24. Infante JR, Peran F, Martinez M, Roldan A, Poyatos R, Ruiz C, Samaniego F, Garrido F: ACTH and b-endorphin in transcendental meditation. Physiol Behav 1998, 64:311-315.

25. Vera FM, Manzaneque JM, Maldonado EF, Carranque GA, Rodriguez FM, Blanca MJ, Morell M: Subjective Sleep Quality and hormonal modulation in long-term yoga practitioners. Biol Psychol 2009, 81:164-168.

26. Lang R, Dehof K, Meurer KA, Kaufmann W: Sympathetic activity and transcendental meditation. J Neural Transm 1979, 44:117-135.

27. Infante JR, Torres-Avisbal M, Pinel P, Vallejo JA, Peran F, Gonzalez F, Contreras P, Pacheco C, Roldan A, Latre JM: Catecholamine levels in practitioners of the transcendental meditation technique. Physiol Behav 2001, 72:141-146.

28. Walton KG, Pugh ND, Gelderloos P, Macrae P: Stress reduction and preventing hypertension: preliminary support for a psychoneuroendocrine mechanism. J Alternat Complement Med 1995, 1:263-283.

29. Solberg EE, Holen A, Ekeberg $\varnothing$, Østerud B, Halvorsen R, Sandvik L: The effects of long meditation on plasma melatonin and blood serotonin. Med Sci Monit 2004, 10:CR96-101.

30. Inoue A, Kawakami N, Ishizaki M, Tabata M, Tsuchiya M, Akiyama M, Kitazume A, Kuroda M, Shimazu A: Three job stress models/concepts and oxidative DNA damage in a sample of workers in Japan. J Psychosom Res 2009, 66:329-334.

31. Yasukawa R, Miyaoka T, Yasuda H, Hayashida M, Inagaki T, Horiguch J: Increased urinary excretion of biopyrrins, oxidative metabolites of bilirubin, in patients with schizophrenia. Psychiatry Res 2007, 153:203-207.

32. Miyaoka T, Yasukawa R, Yasuda H, Shimizu M, Mizuno S, Sukegawa T, Inagaki T, Horiguchi J: Urinary excretion of biopyrrins, oxidative metabolites of bilirubin, increases in patients with psychiatric disorders. Eur Neuropsychopharmacol 2005, 15:249-52.

33. Yamaguchi T, Shioji I, Sugimoto A, Yamaoka M: Psychological stress increases bilirubin metabolites in human urine. Biochem Biophys Res Commun 2002, 293:517-520.

34. Shigenaga M, Gimeno C, Ames B: Urinary 8-hydroxy-2'-deoxyguanosine as a biological marker of in vivo oxidative DNA damage. Proc Natl Acad Sci USA 1989, 86(24):697-701.

35. Yokoyama K, Araki S, Kawakami N, Tkakeshita T: Production of the Japanese edition of profile of mood states (POMS): assessment of reliability and validity. Nippon Koshu Eisei Zasshi 1990, 37:913-918.

36. Waelde LC, Thompson L: A pilot study of a yoga meditation intervention for dementia caregiver stress. J Clin Psychol 2004, 60:677-687.

37. Telles S, Singh N, Joshi M, Balkrishna A: Post traumatic stress symptoms and heart rate variability in Bihar flood survivors following yoga: a randomized controlled study. BMC Psychiatry 2010, 10:18.

38. Pilkington K, Kirkwood G, Rampes H, Richardson J: Yoga for depression: the research evidence. J Affect Disord 2005, 89:13-24.

39. Woolery A, Myers H, Sternlieb B, Zeltzer L: A yoga intervention for young adults with elevated symptoms of depression. Altern Ther Health Med 2004, 10:60-63.

40. Irie $M$, Asami $S$, Ikeda M, Kasai H: Depressive state relates to female oxidative DNA damage via neutrophil activation. Biochem Biophys Res Commun 2003, 311:1014-1018.

41. Irie M, Miyata $M$, Kasai $H$ : Depression and possible cancer risk due to oxidative DNA damage. J Psychiatr Res 2005, 39:553-560.

42. Forlenza MJ, Miller GE: Increased serum levels of 8-hydroxy-2'deoxyguanosine in clinical depression. Psychosom Med 2006, 68:1-7.

43. Greaves-Lord K, Ferdinand RF, Oldehinkel AJ, Sondeijker FE, Ormel J, Verhulst FC: Higher cortisol awakening response in young adolescents with persistent anxiety problems. Acta Psychiatr Scand 2007, 116:137-144.

44. Mannie ZN, Harmer CJ, Cowen PJ: Increased waking salivary cortisol levels in young people at familial risk of depression. Am J Psychiatry 2007, 164:617-621.

45. Jacobs N, Myin-Germeys I, Derom C, Delespaul P, van Os J, Nicolson NA: A momentary assessment study of the relationship between affective and adrenocortical stress responses in daily life. Biol Psychol 2007, 1:60-66.
46. West J, Otte C, Geher K, Johnson J, Mohr DC: Effects of Hatha yoga and African dance on perceived stress, affect, and salivary cortisol. Ann Behav Med 2004, 28:114-118.

47. MacLean CR, Walton KG, Wenneberg SR, Levitsky DK, Mandarino JV, Waziri R, Schneider RH: Altered responses of cortisol, GH, TSH and testosterone to acute stress after four months' practice of transcendental meditation (TM). Ann N Y Acad Sci 1994, 746:381-384

48. MacLean CR, Walton KG, Wenneberg SR, Levitsky DK, Mandarino JP, Waziri R, Hillis SL, Schneider RH: Effects of the Transcendental Meditation program on adaptive mechanisms: changes in hormone levels and responses to stress after 4 months of practice. Psychoneuroendocrinology 1997, 22:277-295.

49. Pawlow LA, Jones GE: The impact of abbreviated progressive muscle relaxation on salivary cortisol. Biol Psychol 2002, 60:1-16.

doi:10.1186/1751-0759-5-6

Cite this article as: Yoshihara et al.: Profile of mood states and stressrelated biochemical indices in long-term yoga practitioners.

BioPsychoSocial Medicine 2011 5:6.

\section{Submit your next manuscript to BioMed Central and take full advantage of:}

- Convenient online submission

- Thorough peer review

- No space constraints or color figure charges

- Immediate publication on acceptance

- Inclusion in PubMed, CAS, Scopus and Google Scholar

- Research which is freely available for redistribution

Submit your manuscript at www.biomedcentral.com/submit
Biomed Central 